\section{International Scientific Journal Theoretical \& Applied Science}

p-ISSN: 2308-4944 (print) e-ISSN: 2409-0085 (online)

Year: 2015 Issue: 10 Volume: 30

Published: $30.10 .2015 \quad$ http://T-Science.org
Nodira Muhtarjanovna Latipova

Candidate of sociological sciences, Docent of the Sociology and social work chair Faculty of social sciences The Mirzo Ulugbek National University of Uzbekistan nodira.L@mail.ru

SECTION 24. Sociological research.

\title{
FEATURES OF THE FAMILY EDUCATION
}

Abstract: This article analyzes the role of the family and the creation of favorable conditions in the family for the upbringing and development of children. The dynamics of changes in the distribution of roles in the family and the influence of the Uzbek family spiritual and the moral education of children.

Key words: Family, children, relationship, family education, children's rights, family roles, egalitarian family, moral education.

Language: Russian

Citation: Latipova NM (2015) FEATURES OF THE FAMILY EDUCATION. ISJ Theoretical \& Applied Science 10 (30): 79-84.

Soi: http://s-o-i.org/1.1/TAS-10-30-19 Doi: crossef http://dx.doi.org/10.15863/TAS.2015.10.30.19

\section{ОСОБЕННОСТИ СЕМЕЙНОГО ВОСПИТАНИЯ}

Аннотация: В статье проанализирована роль семьи и создания в семье благоприятных условий для воспитания и развития детей. Исследована динамика изменений распределение ролей в семье и влияние узбекистанской семьи на духовно-нравственное воспитание детей.

Ключевье слова: Семья, дети, отночения, семейное воспитание, права ребенка, семейные роли, эгалитарная семья, нравственное воспитание.

Значимостью семьи, которая была и остается одним из важнейших социальных институтов в структуре общества, основной функцией которого является рождение и воспитание нового поколения. Именно в семье личность проходит наиболее эффективно первичную социализацию, приобретает необходимые социальные навыки, осваивает базовые ценности и нормы, получает психологическую, экономическую поддержку и защиту.

Здесь формируются ценностномировоззренческие установки и социально-правовые ориентации личности, проявляются её сущностные силы и способности, складываются отношения особого характера. Семейная жизнедеятельность вплетена, в социокультурную реальность связана, с процессами, происходящими в экономике, политике, культуре

В семье формируются настроения людей, их надежды, понимание настоящего, уверенность в будущем, память о минувшем; общественное воспитание человека основывается именно на ценностях, привитых в семье.

В преамбуле Конвенции ООН «О правах ребенка» [4] провозглашается, что ребенку для полного и гармоничного развития его личности необходимо расти в семейном окружении, в атмосфере счастья, любви и понимания.

Семейное воспитание обеспечивает здоровье, физическое, психическое, духовное и нравственное развитие детей, поэтому одним из принципов семейного законодательства Республики Узбекистан является приоритет семейного воспитания детей.

Право несовершеннолетнего жить и воспитываться в семье является одним из важнейших прав ребенка, поскольку семья является естественной средой обитания ребенка, где закладываются предпосылки его физического и духовного развития. С другой стороны, семья является важным институтом гражданского общества, одной из главных функций которого является воспитание детей. От того насколько качественно будет эта функция выполняться, зависит здоровье общества в целом.

C учетом обозначенных социальных процессов закрепление в соответствии со статьей 65. Семейного Кодекса Республики Узбекистан [6] каждый ребенок имеет право жить и воспитываться в семье, право знать своих 
родителей, право на их заботу, право на совместное с ними проживание, за исключением случаев, когда это противоречит его интересам. Ребенок имеет права на воспитание своими родителями, обеспечение его интересов, всестороннее развитие, уважение его человеческого достоинства.

Право ребенка жить и воспитываться в семье следует рассматривать не только в контексте влияния международно-правовых норм на национальное право, но и как результат социальных потребностей в решении наиболее беспокоящих узбекистанское общество вопросов в этой области, к числу которых относятся равная защита интересов семьи, материнства и детства; преодоление проблемы социального сиротства; профилактика жестокого обращения с детьми, безнадзорности.

Говоря о семейном воспитании, прежде всего, следует иметь в виду, что это управляемая система взаимоотношений родителей с детьми. И ведущая роль в этой системе принадлежит родителям. Поэтому именно им необходимо знать, какие формы взаимоотношений с собственными детьми способствуют гармоничному развитию детской психики и личностных качеств, а какие, наоборот, препятствуют формированию у них нормального поведения и в большинстве своем ведут к трудновоспитуемости и деформации личности.
Принято выделять несколько факторов, определяющих семейное воспитание:

- распределение ролей в семье;

- модели отношений родителей с детьми;

- стратегии воспитания (система наказаний и поощрений);

- ценностная ориентация родителей [5].

Семейные роли распределяются в соответствии с тем, кто является главным и кто занимается воспитанием.

По данным социологических исследований Центра изучения общественного мнения «Ижтимоий фикр» на тему «Семья и нравственность» [2], выявлено, что в современном Узбекистане более всего превалирует эгалитарный вид семейных отношений (семья равноправных). Анализ представлений респондентов о том, кто является главой в их семьях (рис 1), в целом подтверждает выявленную на протяжении нескольких лет опроса тенденцию становления нового типа внутрисемейных отношений - на смену традиционной семье, где главой является муж, постепенно приходит эгалитарная семья. Результаты опроса 2014 г. показывают, что наблюдается снижение числа респондентов, указавших на равное главенство мужа и жены в их семьях, по сравнению с данными исследования $2013 \quad$ г. $\quad(33,5 \%$ и $\quad 40,1 \%$ соответственно).

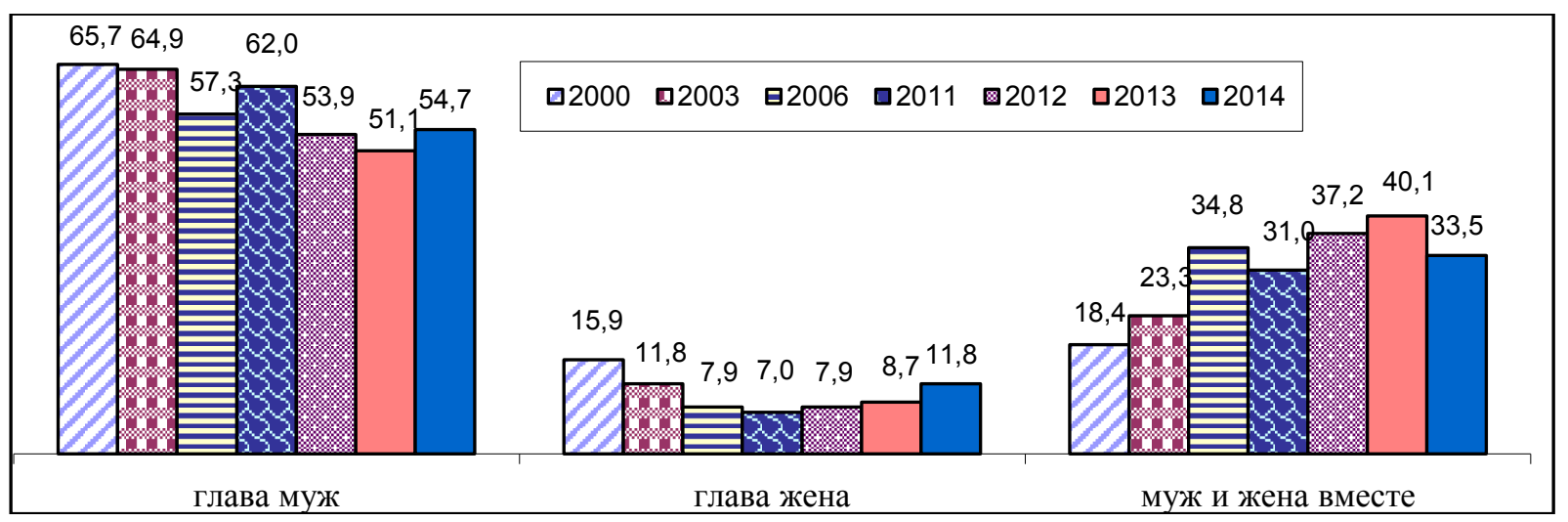

Рисунок 1 - Распределение мнений о лидерстве в семье в целом по выборке, \%.

Примечательно, что, в исследованиях 20122013 гг. мнение о равноправном лидерстве в семье фактически указали меньше женщин (2012 г. $-49,9 \% ; 2013$ г. $-47,4 \%)$, чем мужчин (2012 г. - 60,4\%; 2013 г. - 54,9\%). Результаты опроса 2014г. показывают, что одинаковое количество мужчин и женщин $\quad(33,6 \%$ и $33,5 \%$ соответственно) указывает, что их семьям характерно равное главенство мужа и жены (табл.1). 


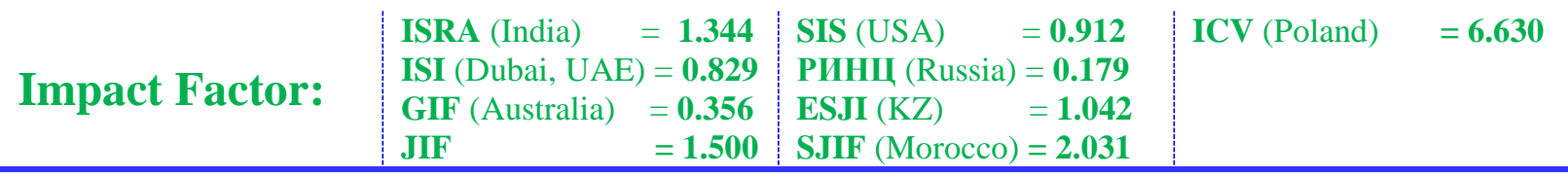

Таблица 1

Распределение мнений о лидерстве в семье с точки зрения мужчин и женщин, \%

\begin{tabular}{|l|c|c|c|c|}
\hline \multirow{2}{*}{} & \multicolumn{2}{|c|}{2013} & \multicolumn{2}{c|}{2014} \\
\cline { 2 - 5 } & Мужчины & Женщины & Мужчины & Женщины \\
\hline Муж & 54,9 & 47,4 & 56,3 & 52,7 \\
\hline Жена & 2,6 & 14,4 & 10,1 & 13,8 \\
\hline Муж и жена вместе & 42,5 & 38,2 & 33,6 & 33,5 \\
\hline
\end{tabular}

Необходимо отметить, что среди опрошенных национальных групп считающих, что в их семье главой является муж, больше представителей узбекской национальности $(60,8 \%)$ по сравнению с представителями национальностей Центральной Азии (48,2\%) и славянских национальностей (29,9\%). В противоположность этому, на то, что в их семьях главой семьи является жена указали 6,9\% представителей узбекской национальности, $22,2 \%$ представителей национальностей Центральной Азии и $34 \%$ представителей славянских национальностей.

Таким образом, современным узбекистанским семьям преимущественно характерно, что главой семья является муж. Однако, наблюдается тенденция постепенной смены традиционной семьи, где главой является муж, на эгалитарную семью или семью равноправных мужа и жены.

Эгалитарная структура, предусматривающая равноправие супругов, как в отношении принятия решений, так и в плане воспитания подрастающего поколения, чаще всего встречается в крупных городах. При эгалитарной структуре к детям относятся как к равным, поощряются терпимость к инакомыслию, в том числе и среди детей, споры детей с родителями.

Анализ результатов опроса [3], показал, что абсолютное большинство респондентов (84,9\%) убеждено в том, что семья оказывает сильное влияние на духовно-нравственное воспитание детей. По данному вопросу наблюдается абсолютное совпадение позиций респондентов независимо от половозрастных, национальных и региональных характеристик (Рис.2).

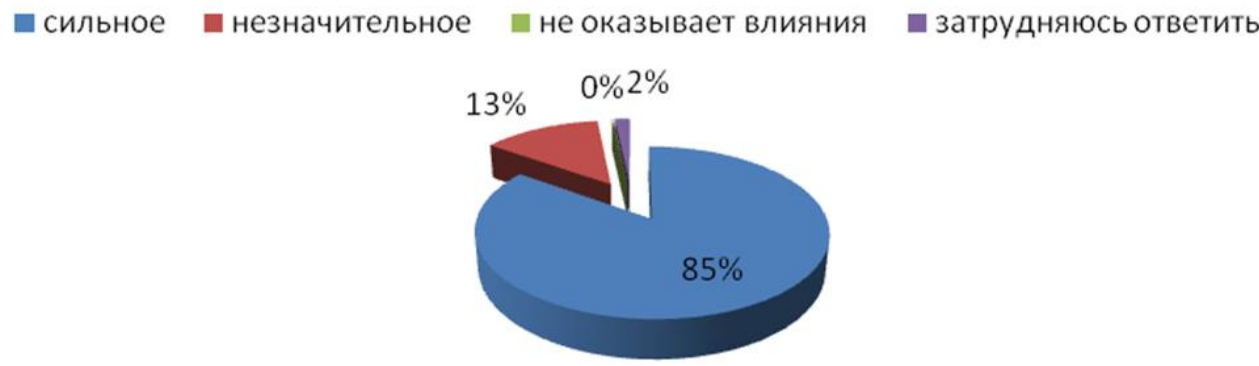

Рисунок 2 - Показатели оценки влияния семьи на нравственное воспитание детей, \%.

Существует свой особый стиль воспитания в каждой культуре, он определяется многими факторами. Респондентам было предложено определить зависимость воспитания от факторов социального статуса и материального положения семьи. Так, более половины опрошенных узбекистанцев, видят прямую зависимость воспитания ребенка от социального статуса родителей и их материального положения независимо от половозрастных, этнических характеристик.

Согласно данным опроса нравственно здоровые, преданные Родине дети воспитываются в трудолюбивых, честных, нравственно здоровых, дружных и мирных семьях. По данной позиции наблюдается полное совпадение взглядов всех групп опрашиваемых.

Таблица 2

Распределение ответов на вопрос: «В каких семьях, на Ваш взгляд, воспитываются нравственно здоровые, преданные Родине дети?», \%.

\begin{tabular}{|l|c|c|c|}
\hline \multicolumn{1}{|c|}{ Тип семьи } & 2012 г. & 2013 г. & 2014 г. \\
\hline В нравственно здоровых семьях & 47,0 & 41,4 & 44,1 \\
\hline В трудолюбивых и честных семьях & 31,2 & 47,9 & 53,6 \\
\hline
\end{tabular}

ISPC Innovations in science, 


\section{Impact Factor:}

\begin{tabular}{ll|lr} 
ISRA $($ India) $=\mathbf{1 . 3 4 4}$ & SIS $($ USA) & $=\mathbf{0 . 9 1 2}$ \\
ISI $($ Dubai, UAE) $=\mathbf{0 . 8 2 9}$ & PИНЩ (Russia) $=\mathbf{0 . 1 7 9}$ \\
GIF $($ Australia) $=\mathbf{0 . 3 5 6}$ & ESJI $($ KZ) & $=\mathbf{1 . 0 4 2}$ \\
JIF & $=\mathbf{1 . 5 0 0}$ & SJIF $($ Morocco $)=\mathbf{2 . 0 3 1}$
\end{tabular}

\begin{tabular}{|l|c|c|c|}
\hline В интеллигентных семьях & 10,4 & 31,6 & 30,1 \\
\hline Дружных и мирных семьях & 8,5 & 41,7 & 38,2 \\
\hline В многодетных семьях & 2,1 & 6,0 & 4,1 \\
\hline В религиозных семьях & 0,7 & 3,6 & 4,5 \\
\hline В материально обеспеченных семьях & 0,1 & 6,4 & 11,0 \\
\hline
\end{tabular}

Также в ходе опроса было изучено мнение респондентов относительно влияния типа распределения власти между членами семьи на нравственное воспитание детей. Половина опрошенных респондентов отмечают, что нравственно здоровые дети воспитываются в семьях, где власть равномерно распределена между отцом и матерью. Каждый третий опрошенный указал, что дети должны воспитываться в атмосфере взаимопонимания и единодушия. $17,9 \%$ опрошенных узбекистанцев полагают, что нравственное воспитание может обеспечить детям семья, в которой отец является главой семьи.
Нравственные ценности усваиваются в детстве, посредством трансляции социального опыта в семье и развиваются в каждом человеке в течение всей его жизни под воздействием общества. Совокупная самооценка значимости внимания, которое уделяют, узбекистанцы нравственному воспитанию детей составляет, 92,9\%. Таким образом, можно сделать вывод, что узбекистанцы воспитывают детей в духе высоких моральных принципов и формирования нравственных качеств.

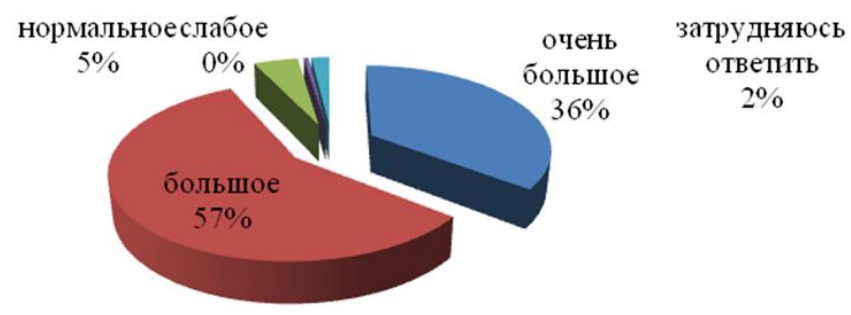

Рисунок 3 - Показатели самооценки внимания нравственному воспитанию детей, \%.

На формирование у детей честности, правдивости, трудолюбия обращают внимание большинство опрошенных узбекистанских семей. Значительными базовыми нравственными ценностями, которые стараются привить опрошенные родители детям, были также обозначены скромность, уважение к старшим и послушание родителей. Респонденты, проживающие, в сельской местности стараются, обращать первостепенное внимание в нравственном воспитании уважения к старшим, патриотизму и любви к Родине. Горожане же стремятся привить такие качества как честность, правдивость, скромность, трудолюбие, уважение к старшим, патриотизм, любовь к Родине. Наблюдается совпадение мнений в оценке степени важности формирования у детей нравственных качеств мужчин и женщин.

Цель каждого ответственного родителя воспитать честных, порядочных, высоконравственных граждан. Абсолютное большинство респондентов выражают уверенность в том, что их дети вырастут гармонично развитыми личностями. Из них полную уверенность выразили $37 \%$ респондентов и среднюю степень уверенности проявили 53,9\% опрошенных узбекистанцев, лишь $4,8 \%$ опрошенных выразили частичную уверенность. Необходимо отметить тот факт, что ни один респондент не выбрал вариант ответа «нет, не верю».

Анализ опроса показал, что узбекистанцы считают основными нравственными качествами личности патриотизм, любовь к Родине (49,9\%), хорошее знание истории своего народа $(45 \%)$, уважение национальных традиций $(42,6 \%)$. Важными категориями нравственности, по мнению опрошенных, являются честность $(34,9 \%)$, развитое чувство национальной гордости и самосознания $(23,2 \%)$, чистота души $(23,2 \%)$, скромность $(19 \%)$, трудолюбие $(13,5 \%)$, религиозная и национальная толерантность (12,5\%), негативное отношение к религиозному экстремизму (7,3\%). 
Наблюдается разница во взглядах представителей разных национальностей. Так, для большинства представителей узбекской национальности основополагающими нравственными ценностями являются патриотизм, любовь к Родине, хорошее знание истории своего народа, уважение национальных традиций. Славяне в свою очередь выделяют чистоту души, трудолюбие.

Bce вышеперечисленные качества респонденты проранжировали по степени важности в воспитании гармонично развитой личности. Так, более половины опрошенных указали, что основное внимание в процессе воспитания гармоничной личности следует уделять формированию трудолюбия в детях. $46,9 \%$ респондентов считают, что упор в воспитании необходимо делать на учебу, 45,1\% на послушание родителям, 39,6\% опрошенных узбекистанцев отметили важность формирования нравственности у детей. Необходимо отметить, что немаловажными ценностями нравственного воспитания респонденты считают честность, патриотизм, любовь к Родине, самостоятельность, доброту и скромность.

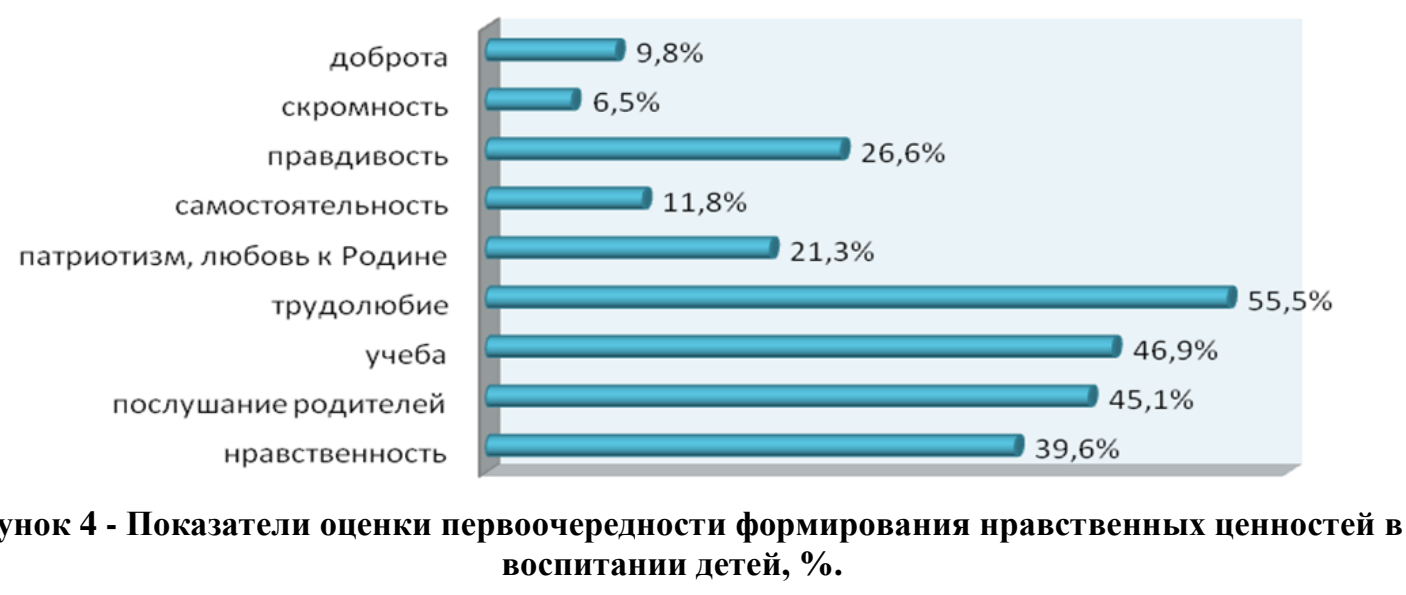

Нравственные ценности усваиваются в детстве, посредством трансляции социального опыта в семье и развиваются в каждом человеке в течение всей его жизни под воздействием общества. Совокупная самооценка значимости внимания, которое уделяют, узбекистанцы нравственному воспитанию детей составляет, 92,9\%. Таким образом, можно сделать вывод, что узбекистанцы воспитывают детей в духе высоких моральных принципов и формирования нравственных качеств.

Модели отношений между родителями и ребенком определяются не только распределением ролей, но степенью эмоциональной отзывчивости и воспитательной уверенности родителей. Наиболее тяжелые последствия для ребенка оставляют эмоциональное отвержение, безразличие. Дети, воспитанные без родительской любви, отстают в интеллектуальном развитии, они отличаются эмоциональной незрелостью, повышенной агрессивностью, появлением чувства «выученной беспомощности». Все это приводит к апатии, потере любознательности и инициативы, страху перед новыми ситуациями и людьми.

Данные сцинтиграфии головного мозга [1] показали, что существуют различия в структуре головного мозга у ребенка, воспитывающегося в Доме ребенка и в заботливой семье.

ISPC Innovations in science,

Harrisburg, USA

Институционализация воздействует на развитие мозга маленьких детей следующим образом: снижает и/или изменяет активность мозга, особенно в предлобной и височной частях головного мозга, отвечающих за познавательную деятельность, память и эмоции; изменяет ключевые гормоны; изменяет размер мозга в некоторых его частях; изменяет взаимосвязи между частями мозга, что приводит к серьезным последствиям в отношении физического, познавательного, социального и эмоционального развития.

Результаты исследований специалистов Республиканского Центра социальной адаптации детей (РЦСАД) показали, что даже кратковременное содержание детей в институциональных учреждениях, имеющих своих родителей, способствует нарушению социальной идентичности ребенка, формированию у них агрессивности в отношении своих близких, нарушению социальной компетенции и т.д [7, с. 13]. Наряду с этим, у родителей развивается отстраненность от своих родительских обязательств, что способствует деградации семейных ценностей, как у взрослого, так и у ребенка. Специалисты РЦСАД активно пропагандируют и ведут работу по возвращению детей к своим родителям (за последние 3 года около 300 случаев возврата). Однако, как показали психологические исследования, после 
воссоединения семьи наблюдается искаженное развитие семейных взаимоотношений и проблемы в восстановлении детско-родительских отношений, что еще раз доказывает необходимость оказания социальной, психологической помощи семье до поступления ребенка на государственное обеспечение и предотвращения разлучения детей с родителями.
В связи с этим можно предположить, что требованием времени является всестороннее и гармоничное развитие ребенка в семье. Для достижения гармонии в развитии ребёнка необходимо уделять внимание не только интеллектуальному, эмоциональному, нравственному развитию, но и его и физическому совершенствованию.

\section{References:}

1. Brutman VI, et al. (1994) Rannee social'noe sirotstvo (mediko-social'no-psihologicheskie problemy). Uchebno-metodicheskoe posobie. Moscow: Izd. jeks. kompleksa social'noj pomoshhi detjam i podrostkam Mos. dep. obrazovanija, 1994.

2. (2014) Issledovanie provedeno v 2014 goda na territorii vseh regionov Uzbekistana - v g.Tashkente, Respublike Karakalpakstan, Andizhanskom, Buharskom, Dzhizakskom, Kashkadar'inskom,

Namanganskom, Navoijskom,

Surhandar'inskom, Samarkandskom, Syrdar'inskom, Tashkentskom, Ferganskom, Horezmskom vilojatah. Vsego oproshennyh - 1100 chelovek, $\mathrm{v}$ tom chisle muzhchin - 53,9\%, zhenshhin $46,1 \%$

3. (2014) Issledovanie provedeno v 2014 goda na territorii vseh regionov Uzbekistana - v g.Tashkente, Respublike Karakalpakstan, Andizhanskom, Buharskom, Dzhizakskom, Kashkadar'inskom,

Namanganskom, Navoijskom, Surhandar'inskom, Samarkandskom, Syrdar'inskom, Tashkentskom, Ferganskom, Horezmskom vilojatah. Vsego oproshennyh - 1100 chelovek, $\mathrm{v}$ tom chisle muzhchin $-53,9 \%$, zhenshhin $46,1 \%$.

4. (1992) Mezhdunarodnaja Konvencija OON po Pravam Rebenka. UNICEF, Detskij fond OON, 1992.

5. (2015) Semejnoe vospitanie. Available: http://www.neboleem.net/stati-o-detjah/6696semejnoe-vospitanie-detej.php (Accessed: 20.10.2015).

6. (2012) Semejnyj kodeks Respubliki Uzbekistan. - Tashkent: Adolat, 2012.

7. Hrul'nova G (2015) Zadachi modernizacii sistemy profilaktiki rannego social'nogo sirotstva V Uzbekistane // Respublikanskaja konferencija «Razvitie uslug po podderzhke sem'i: mezhdunarodnyj i mestnyj opyt. Urgench. 11-12 june 2015. - pp.12-14.

8. Karimov IA (1997) Uzbekistan na poroge XXI veka: ugrozy bezopasnosti, uslovija i garantii progressa. T.: Uzbekiston, 1997.

9. (2013) Konstitucija Respubliki Uzbekistan. T.: Uzbekiston, 2013. 40 p.

10. (2003) Ideja nacional'noj nezavisimosti: osnovnye ponjatija i principy. T.: Uzbekiston, 2003. 